\title{
DE VÁRZEA A PARQUE: ESTUDO ANTROPOLÓGICO DAS DIFERENTES FORMAS DE SOCIABILIDADE NO ESPAÇO DO PARQUE DA REDENÇÃO
}

\author{
Elenir Sandra Tartas da Rosa \\ Ana Luiza Carvalho da Rocha (Orientação)
}

Pretendo com esse estudo analisar a relação entre as diferentes formas de sociabilidade encontradas no Parque da Redenção e as formas de apropriação espacial dos frequientadores desse Parque estabelecidas ao longo do tempo. Para isso, nessa fase inicial da pesquisa, parto da verificação das transformações que ocorreram nesse espaço através do estudo de mapas, fotografias históricas e textos escritos por cronistas ${ }^{1}$, juntamente com as entrevistas informais realizadas em campo, na tentativa de compreender como esse espaço foi

constituído e como hoje ele é ocupado.

Notei com o decorrer do tempo de pesquisa que para poder falar desse espaço, da sua constituição como Parque e das formas de sociabilidade encontradas nele, era necessário que eu fizesse algumas leituras a cerca da história de Porto Alegre e da formação desse Parque, e que me familiarizasse com as diferentes denominações que foram dadas a ele na sua trajetória histórica, aumentando dessa forma a minha percepção com relação ao tempo e espaço presentes na memória coletiva trazidas pelos freqüentadores desse Parque. Então, para que eu pudesse localizar o surgimento do Parque num contexto urbano da cidade, busquei em autores como (Macedo, 1973) ${ }^{2}$ e (Monteiro, 1989) ${ }^{3}$ compreender como era esse espaço no final do século XIX e início do XX. Também foi

\footnotetext{
${ }^{1}$ Foi fundamental a leitura das crônicas de autores como (Porto Alegre, 1940) e (Coelho, 1935) para a construção visual de uma Porto Alegre antiga, principalmente, do cotidiano do centro e arrabaldes que cercavam o "Campos da Várzea", hoje Parque da Redenção.

2 (Macedo, 1973) vai falar do Parque da Redenção e trazer mapas e projetos de melhoramentos desenvolvidos para o "Campos da Várzea".

3 Foram fundamentais as leituras da Monografia e do artigo do historiador Charles Monteiro, principalmente, por ele falar das diferentes formas de sociabilidade que vão aparecendo nesse espaço em meio a um desenvolvimento urbano da cidade.
} 
necessário recorrer a análise de material fotográfico (Leite, 2001) ${ }^{4}$ do período de 1900 1935, e das décadas de 40, 50 e 605. Com o acesso a essas fotografias está sendo possível observar as transformações espaciais desse Parque, as práticas e sociabilidade que se desenrolavam nesse local e as classes sociais presentes durante essas diferentes épocas. Nesse momento a leitura de cronistas que falassem do cotidiano do "Campos da Várzea" (Porto Alegre, 1940) ${ }^{6}$ tornou-se muito importante para definir meu próprio imaginário a respeito desse espaço antigo.

\section{A Demarcação dos Espaços do Parque}

O Parque da Redenção localiza-se entre os bairros Bom Fim, Cidade Baixa, Santana e Centro da cidade. Na lateral desse Parque encontram-se as Avenidas João Pessoa (antigo Caminho da Azenha) e Osvaldo Aranha (antigo Caminho do Meio). Esses eram os caminhos que ligavam o centro da cidade aos antigos arraiais, hoje bairros de nossa capital.

Mapa de Porto Alegre/1820

Fonte:
Mapa de Porto Alegre/1850

Fonte:

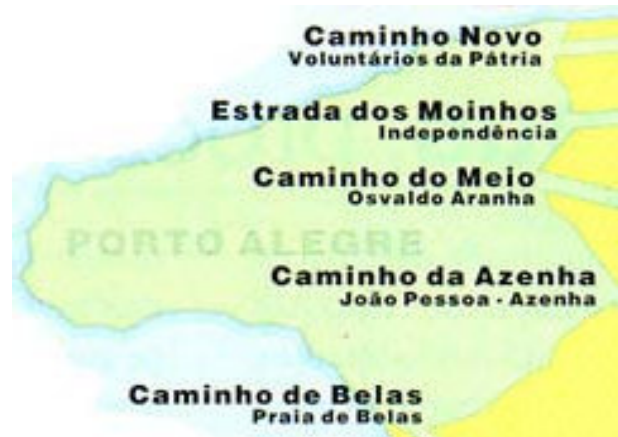

A nova expansão

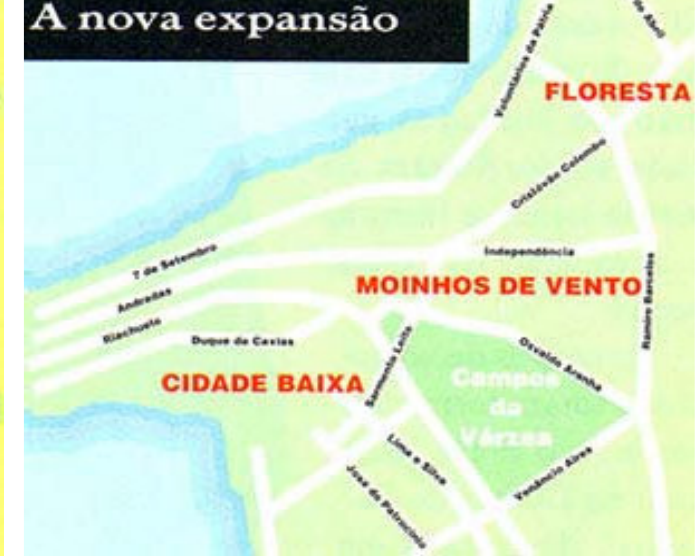

${ }^{4} \mathrm{O}$ método desenvolvido por essa autora para a leitura de imagens, sejam fotografias, mapas ou desenhos além de me auxiliarem na organização das imagens que encontrava do Parque da Redenção, também mostraram-me a importância dessas imagens para retratar esse espaço antigo.

5 Essas imagens foram encontradas através da pesquisa do acervo nas Revistas do Globo disponíveis no Banco de Imagens e Efeitos Visuais.

${ }^{6}$ Era dessa forma que a população de Porto Alegre se referia ao espaço que conhecemos hoje como

Parque da Redenção. 
Foi a partir do contato e análise dos mapas (Macedo, 1940) ${ }^{7}$ e das fotografias antigas $^{8}$ do "Campos da Várzea" é que pude entender como esse espaço foi ocupado no decorrer da sua história.

Esses itinerários que ligavam os arrabaldes ao centro da cidade foram importantes na delimitação do espaço que mais tarde passaria a ser ocupado pelo Parque. No entanto, o fato desse local ter sido um campo alagadiço, de difícil acesso e impróprio para deslocamentos da população é que as extremidades dele foram sendo desenhadas pelos caminhos recorrentes usados pela população que vivia nos arraiais e que precisava chegar ao centro da cidade.

Com o avanço das leituras no reconhecimento de uma cidade antiga passei a questionar essa separação espacial e os caminhos criados pela comunidade da época como criadores também de "fronteiras" entre um espaço e outro. Segundo DaMatta, tanto tempo quanto espaço são invenções sociais, para explicar como o espaço é demarcado pela sociedade temos que entender essas separações, de que modo elas são feitas "e como são legitimadas e aceitas pela comunidade da propriedade privada e suas origens". (DaMatta, 1997: 32$)^{9}$

A primeira denominação dada ao local foi o de "Campos da Várzea", no início do século XX, e compreendia a extensão que vai da atual Av. Venâncio Aires até a Praça Argentina, inclusive o espaço ocupado pelos prédios da UFRGS. Com a construção da Igreja do Bom Fim, a várzea passou a ser chamada de "Campos do Bom Fim", e várias atividades religiosas passaram a se desenvolver nessa área, como quermesses e procissões. Mais tarde, quando da libertação dos escravos, a população passou a chamá-lo de "Campos da Redempção".

Além de todas essas atividades que foram demarcando os espaços de sociabilidade no que hoje conhecemos como Parque, também dois eventos foram significativos para a

\footnotetext{
${ }^{7}$ Planta de Porto Alegre de 1837 (p. 100), Planta da Grande Exposição de 1901 (p.106), Plano Geral de Melhoramentos de 1914 (p. 110), Ante Projeto de Ajardinamento do Campo da Redenção do ano 1930 (p. 111) e Planta do Parque da Redenção durante a Exposição de 1935 (p. 115).

${ }^{8}$ As fotografias antigas e atuais, mapas e plantas usadas nesse trabalho estão disponíveis no Banco de Imagens e Efeitos Visuais, no Instituto Latino Americano (ILEA), Campus do Vale, UFRGS.

${ }^{9}$ Roberto DaMatta vai estar discutindo a noção que os atores sociais tem a respeito de tempo e espaços público e privado.
} 
apropriação desse espaço público. O primeiro ocorreu em 1901, quando se realizou em Porto Alegre, no "Campos da Redempção", a grande Exposição Estadual. Na ocasião, além de urbanizar uma parte desse espaço também se propiciou o ajardinamento dele. Os pavilhões que receberam os comerciantes de todo o estado foram distribuídos no local que hoje pertence ao Campus Central da UFRGS. Já nesse período encontrava-se lá instalado o prédio da Engenharia, e dois importantes espaços que abrigavam diferentes formas de sociabilidade da época que eram o "Circo de Touradas" e o "Velódromo". Além dos pavilhões da exposição foram construídos outros locais de sociabilidade como cafés, teatro e recantos com jardins.

"Toda vez que eu passo ou penetro no jardim do Parque, como ficou chamado e é conhecido o da Escola de Engenharia, não posso fugir ao impulso de furtar uma rosa para florir a pequena jarra da minha modesta mesa de trabalho. (...) o pequeno 'Theatro-Parque', era páo p'ra toda obra. Servia para casa de espectaculo e funcções: dramaturgia, acrobaica, perstidigitação e 'tout le mode et son père'." (Porto Alegre, 1940:110) ${ }^{10}$

Nessa crônica pode-se perceber o quanto foi significativo para configuração espacial e social do "Campos da Redempção" a criação de novos espaços de sociabilidade. Através desse tipo de documento podemos obter informações e registros dos acontecimentos da época na medida em que mostram a importância que eles tiveram para a memória coletiva que se tem desse Parque (Le Goff, 1992:4). Mesmo com o término da exposição os pavilhões, cafés, teatro e jardins permaneceram alojados no "Campos da Redempção" o que possibilitou aos portoalegrenses desfrutar desses espaços por um maior tempo.

O segundo evento foi importante para a consolidação do espaço semelhante ao que conhecemos hoje, foi o da Exposição de 1935, organizada em homenagem ao Centenário

\footnotetext{
${ }^{10}$ Essa crônica tem como título "O Theatro-Parque" e foi escrita em 1902. Ela retrata a importância que esses espaços de sociabilidade ocuparam no cotidiano dos portoalegrenses.
} 
Farroupilha. Para que ela acontecesse foi adotado, em parte, o ante-projeto de ajardinamento ${ }^{11}$ previsto para área em 1930 (Macedo, 1973:111). No projeto que foi realizado aproveitou-se a extensão que o "Campos da Redempção" oferecia para criar um grande lago, chafariz e traçar caminhos que unissem os espaços. O desenho de um eixo central ligando o Monumento ao Expedicionário aos prédios da UFRGS foi muito importante para a configuração do Parque que nós conhecemos hoje.

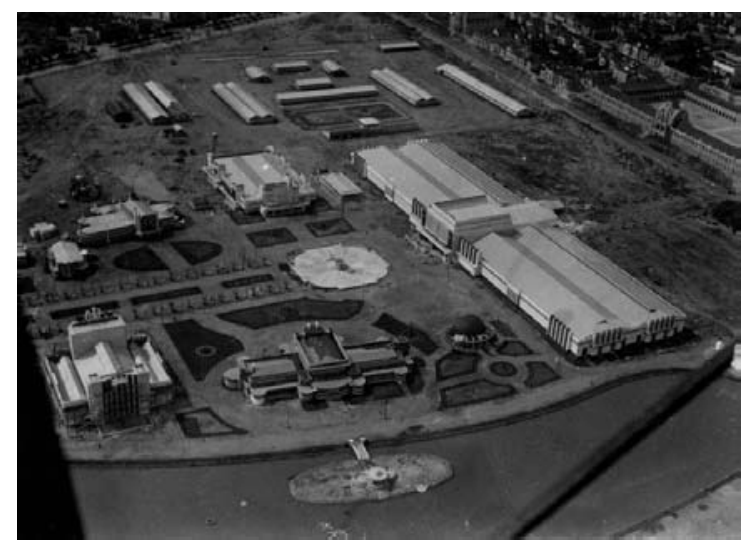

Vista aérea da Exposição de 35

Fonte: Biev - Banco de Imagens e Efeitos Visuais

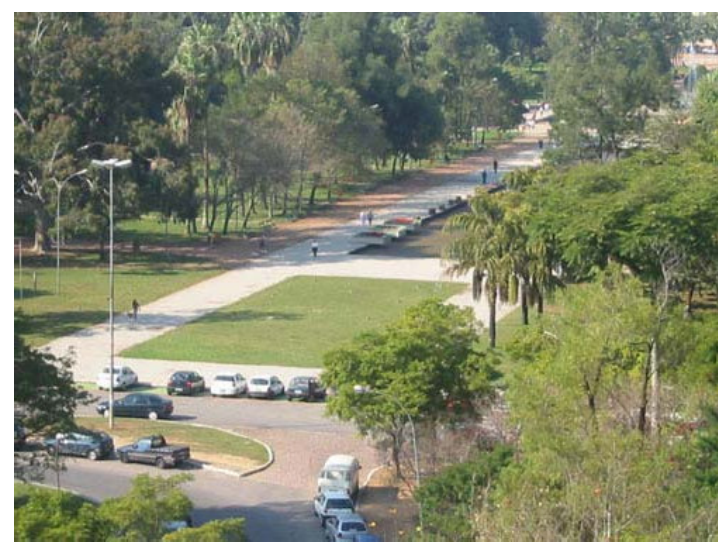

Elenir Sandra Tartas da Rosa, 2003 Fonte: Biev - Banco de Imagens e Efeitos Visuais

Observando as fotografias e andando pelo Parque da Redenção percebi que muitos dos traçados feitos para abrigar essa Exposição estão presentes ainda hoje como o lago, o eixo central com chafariz e alguns caminhos periféricos. A partir desse evento mudou-se o nome oficial do "Campos da Redempção" para "Parque Farroupilha", denominação pouco usada pela população de Porto Alegre.

Com as entrevistas feitas com os freqüentadores do Parque percebi que eles mantêm fortes laços de pertencimento com o local, independente das modificações efetuadas no espaço ou das diferentes denominações dadas a ele ao longo do tempo. Os entrevistados referem-se a esse Parque como "Parque da Redenção", ou simplesmente "Redenção". DaMatta vai dizer que existe uma noção de tempo e outra de espaço, ao mesmo tempo em

\footnotetext{
${ }^{11}$ O "Ante-projeto de Ajardinamento do Campo da Redempção" foi desenvolvido pelo arquiteto Alfredo Agache em 1920.
} 
que essas noções constroem, também "são construídas pela sociedade dos homens." (DaMatta, 1997: 33)

\section{Espaços de Sociabilidade}

Existem duas extremidades que delimitam o eixo central do Parque: de um lado temos o acesso ao Campus Central da UFRGS e no outro a Rua José Bonifácio com o seu prédio mais antigo, o Colégio Militar de Porto Alegre.

É nessa rua que nos finais de semana acontecem eventos importantes no que diz respeito a trocas sociais em Porto Alegre. Nos sábados realiza-se a "Feira Ecológica da Coolméia" e nos domingos instala-se o "Brique da Redenção", tradicional ponto de encontro de diferenciados grupos sociais. Essa concentração de atores sociais, vindos de diversos bairros atraídos por esses eventos, demonstra outras formas de sociabilidade coletivas significativas para a identidade porto-alegrense.

Porém, nesse primeiro momento de pesquisa pretendia participar da cotidianiedade dos encontros, trocas e relações sociais realizadas diariamente nesse local. Assim, no mês de outubro de 2002 passei a freqüentar o Parque uma vez por semana, em dias e horários variados, na tentativa de perceber esse cotidiano.

Já nos primeiros dias em campo ingressei no cotidiano do Parque através das entrevistas informais feitas no local. Constatei que muitos dos freqüentadores do Parque são moradores dos bairros que o cercam, no entanto, alguns vêm de bairros distantes da cidade para poder caminhar e correr nele. Esse fato foi revelado através dos relatos que me foram feitos no próprio local por freqüentadores que moram nos bairros que o circundam. Como exemplo dessas conversas segue abaixo um trecho tirado de um diário de campo realizado numa manhã de sexta-feira.

"Eu venho aqui quase todos os dias, a [fulana] é que vem a 6:30, né [fulana]? [a outra respondeu] "Sim todos os dias. Faço uma caminhada de uma hora todos os dias pela manhã, bem cedo. Depois vou prá casa e volto com o chimarrão. Eu adoro! E nos dias de 
chuva? [perguntei e ela respondeu] ... é uma tristeza... [com tom de lamento e continuou] se não chover forte... às vezes venho até de guarda-chuva [risos]."

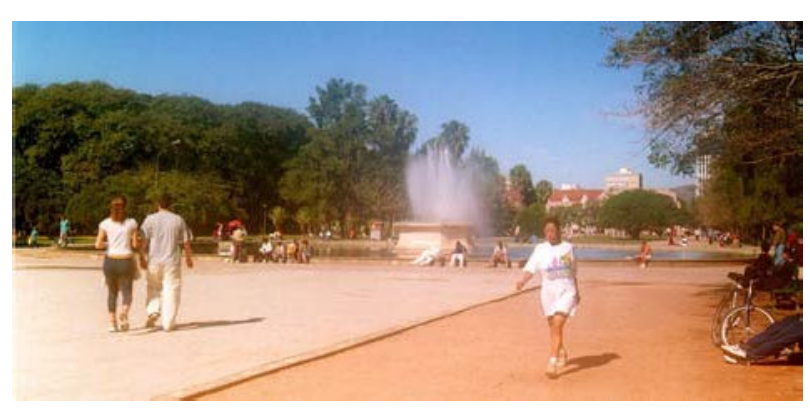

Elenir Sandra Tartas da Rosa, 2002 Fonte: Biev - Banco de Imagens e Efeitos Visuais

$\mathrm{O}$ deslocamento das pessoas na cidade para encontrar nesse espaço lazer e divertimento, é uma prática que teve seu início ainda entre os moradores dos arrabaldes quando ele era um campo alagadiço. As práticas esportivas foram se desenhando na memória desse espaço desde o início do século XIX. A primeira que se tem notícia foram as corridas de cavalo que aconteciam nos finais de semana, proporcionando divertimento aos moradores dos arrabaldes.

\footnotetext{
"Antigamente quando não tínhamos ainda hipodromos, as corridas de cavalos eram realizadas num trecho da estrada ou alí na Várzea nas imediações do colégio militar. Esta era a cancha preferida. Ali se reuniam aos domingos e dias feriados, os moradores dos subúrbios e dos povoados vizinhos que tinham paixão pelas corridas de cavalos." (Porto Alegre, 1940:

$100)$.
}

Andando por entre os caminhos laterais do Parque em horários diferenciados do dia notei que existe uma heterogeneidade de práticas e trocas entre os freqüentadores e os passantes que atravessam o Parque. Muitas pessoas usam o Parque como um atalho entre as avenidas Osvaldo Aranha e João Pessoa.

Nesses locais encontrei casais de namorados que costumam ficar sentados em bancos e trocar afagos e beijos, não se importando com as pessoas que transitam e os olham com muita curiosidade. 


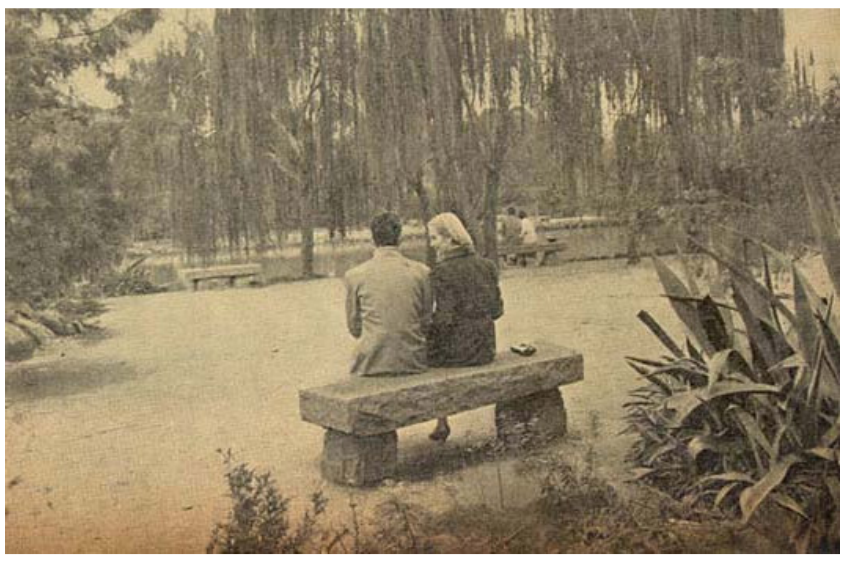

Desconhecido, 1950

Fonte: Revista do Globo

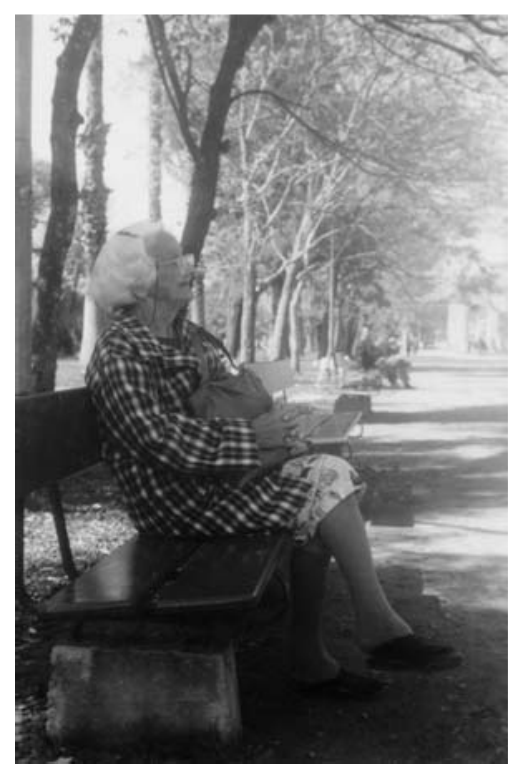

Elenir Sandra Tartas da Rosa, 2002 Fonte: Biev - Banco de Imagens e Efeitos Visuais

Também observei que nos recantos mais sossegados a presença de alguns solitários que fazem do hábito da leitura e do local pouco visitado "refúgio" da vida tumultuada das grandes cidades.

Nessas extremidades do Parque, nesses caminhos que fazem divisas com as ruas, podemos encontrar pessoas correndo, caminhando ou passeando. Porém, nesses locais as formas de sociabilidade entre os freqüentadores não acontecem com tanta intensidade quanto no eixo central. Em uma manhã em que andava num caminho próximo a Av. Osvaldo Aranha encontrei uma das minhas informantes que é integrante da "rede de desportistas ${ }^{12,}$. Todas as vezes que a vi estava acompanhada, no entanto, nesse dia caminhava sozinha e com muita pressa.

“... não vou mais caminhar lá dentro. [apontando para o eixo central do Parque] Porque? [ela respondeu] Tu tem que parar cada pouco pra cumprimentar alguém, não dá! Hoje, resolvi caminhar por fora. [referindo-se

\footnotetext{
${ }_{12}$ Nominei as redes sociais que encontrei no Parque na tentativa de poder distinguir uma das outras nas suas práticas variadas.
} 
aos caminhos laterais do Parque] Aqui sim é bom. Parece que ninguém te conhece, porque ninguém te para cada pouco prá conversar. [notei que não era o momento ideal para conversar e falei] É, nós vemos daqui pouco, lá...[apontei para o eixo central]".

Para entender como esses atores sociais se percebem nesse espaço público e como eles transitam entre os espaços público e privado foi fundamental recorrer a autores como (Velho, 1981 e 1994), (DaMatta, 1997) e (Hall, 1973) ${ }^{13}$, porque além de me fornecerem instrumentos teóricos para a compreensão das relações entre os atores sociais nos espaços públicos, também foram importantes na medida em que estudam as interações trocadas entre os atores na complexidade das sociedades modernas.

Em algumas tardes enquanto pesquisava observei que algumas crianças costumam banhar-se nas águas da Redenção nos períodos mais quentes do ano.

Os locais preferidos por essa população infantil vinda dos bairros mais longínquos da cidade são o Chafariz e o Lago da Redenção. Foi nesses locais que encontrei muitos menores com idade entre 8 e 16 anos, buscando uma boa oportunidade para se divertir e mergulhar naquelas águas escuras. Essa prática é muito comum nos dias de calor mais intenso.

Essas crianças pulavam e gritavam sem se importar com alguns freqüentadores que passavam e não cansavam de perguntar "como podiam" aquelas crianças entrar na água suja e poluída do Chafariz.

Enquanto que alguns freqüentadores "fazem de conta" de que nada está acontecendo e que a presença dessas crianças não atrapalha a sua rotina. Existem outros porém que reclamam indignados pela freqüência em que esses banhos acontecem e a pouca preocupação dessas crianças com o estado da água, esse fato enfurece essas pessoas que reclamam das "autoridades" que não proíbem essas práticas dos menores no Parque.

Já, os "quase adolescentes" com idade entre 11 e 16 anos procuram nas águas sujas do Lago o frescor para as tardes mais quentes, brincando e saltando em busca do melhor"bico". Nesse local são poucas as pessoas que se importam com a presença desses jovens.

13 A noção de territorialidade e interação entre os homens e os espaços vai ser trabalhada por esse autor. 

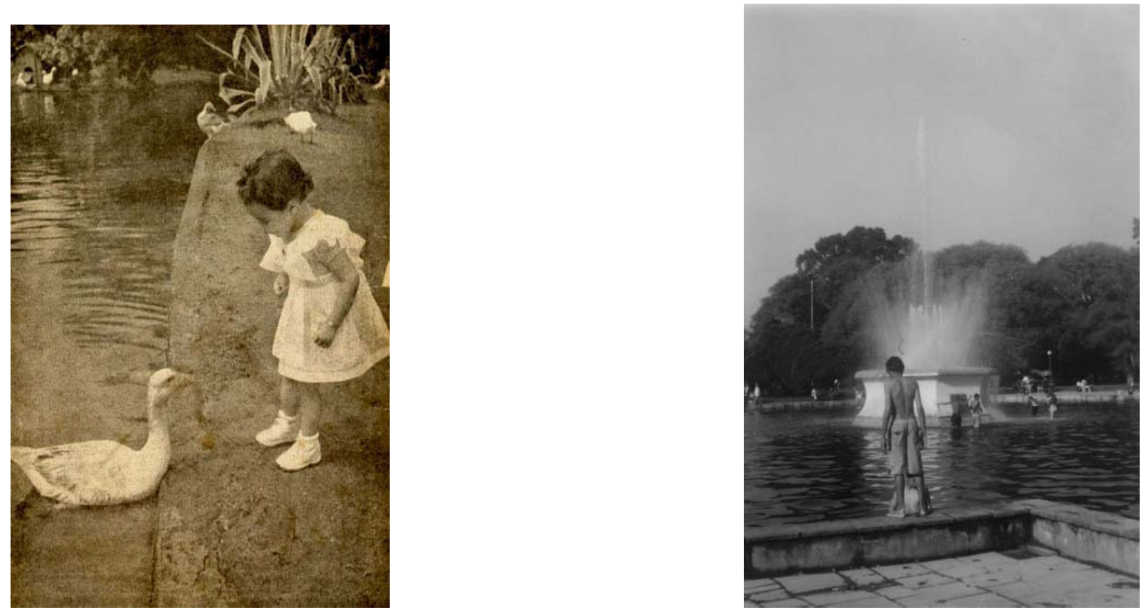

Já, os "quase adolescentes" com idade entre 11 e 16 anos procuram nas águas sujas do Lago o frescor para as tardes mais quentes, brincando e saltando em busca do melhor "bico". Nesse local são poucas as pessoas que se importam com a presença desses jovens. Eles não são maltratados, mas também não há um convite para que eles interajam com a rotina de quem fica sentado no Café ou nos bancos próximos ao Lago.

Segundo Gilberto Velho, é comum encontramos "coexistência de diferentes estilos de vida e visão de mundo" (Velho, 1981:17) ocupando mesmo espaço e compartilhando a mesma realidade. A simbologia de um Parque como um local em que se pode relaxar, encontrar amigos e passear pode variar de acordo com o estilo de vida de cada indivíduo. Até mesmo a maneira como esses atores vão ocupar esses espaços está sujeita ao modo de vida em que essas pessoas vivem e as práticas cotidianas ligadas a determinados espaços.

Quando o Parque ainda era um campo alagadiço e servia de repouso aos tropeiros e comerciantes já abrigava diferentes formas de sociabilidade entre os moradores dos arrabaldes e os vizinhos mais distantes.

"Os carreteiros, em numerosas carretas, chegavam á Varzea geralmente pela estrada do meio, largavam bois proximo á chacara do Major Moraes. (...) A mercadoria das carretas era logo atacada pelos moradores mais proximos, e contava de excellentes rapaduras em formato de queijo, orijones de pecegos, bananas, (...) Eram os dias mais alegres para aquella população, a feira rural que vinha em visita á Capital". (Coelho, 1935: 32) ${ }^{14}$ 
Pude observar através das fotografias e dos cronistas como se davam essas diferentes formas de sociabilidade e a apropriação com que foi feita no espaço. Como exemplo disso trago essa fotografia que é datada do início do século XX. Em primeiro plano vemos os pavilhões da Exposição de 1901. Em segundo plano, ainda não ajardinado o "Campos da Várzea". Atrás desses pavilhões do lado esquerdo da foto localizava-se o Velódromo e a direita próximo ao Caminho da Azenha (hoje Av. João Pessoa) o Circo de Touradas.

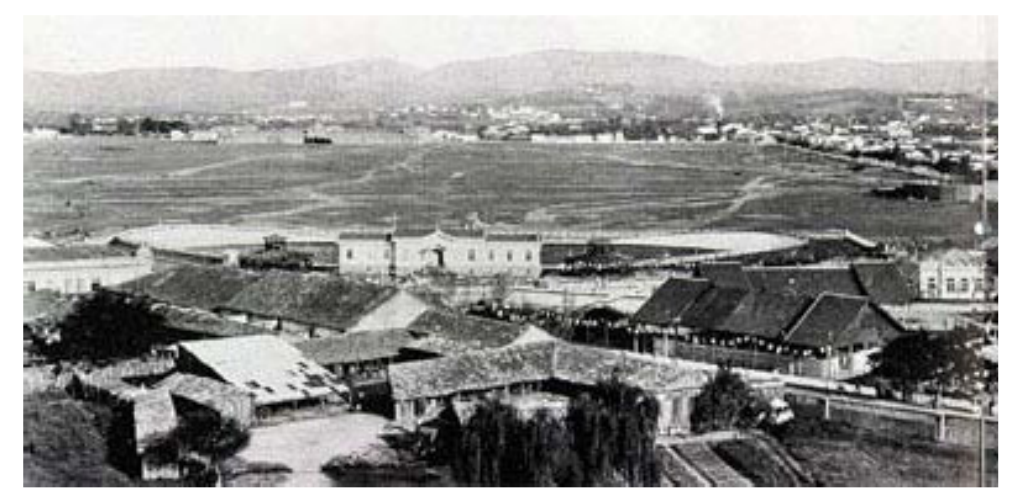

Lunara Amador, inicio do seculo XX

Com a construção desses espaços sociais no "Campos da Várzea", houve uma modificação das formas de sociabilidade trocadas nesse local. Por serem locais fechados e preservarem a segurança dos freqüentadores, a classe alta portoalegrense passou a ser vista na várzea com maior freqüência e a interagir com a população menos favorecida que vivia nos arrabaldes.

"Há cerca de quarenta annos, [1880, mais ou menos] (...) O que é verdade é que aos domingos o 'circo' da Várzea se enchia de uma multidão tumultuária e multicôr. Havia entradas para o sol e para a sombra. As do sol custavam a metade das outras, mas os 'habitués' não faziam questão disso: o que queriam era entrar, custasse o que custasse, pagassem quanto pagassem. Era desde da 'arraia meuda', ao scol social." (Porto Alegre, 1940: 89) 15

14 Essa crônica fala do cotidiano na várzea e, principalmente, das interações dos moradores dos arrabaldes nesse espaço.

15 Essa crônica foi escrita por volta de 1920. Mas, o seu texto tem como referência o cotidiano do "Campos da Várzea” em 1880. 
"As touradas eram um dos divertimentos mais atraentes e que mais mobilizavam a população daquela Porto Alegre do fim do século. O Circo de touradas tinha arquibancada de madeira e um trecho coberto para comportar as pessoas de status. (...) Já as corridas de Cavalos não eram tão bem freqüentadas assim. Era coisa mais popular e não atraia os elegantes e gente fina." (Luis Carlos Carneiro e Rejane Penna, 1992:53)

Essas interações entre os atores de diferentes classes sociais continuam a acontecer nesse espaço. Porém, notei nesses primeiros contatos com os freqüentadores que as formas de sociabilidade decorrentes deles não são tão "intensas" quanto as trocadas entre os integrantes das diferentes redes encontradas no Parque.

\section{As Diferentes Redes no Parque, suas Práticas e Formas de Sociabilidade}

Circulando pelo Parque da Redenção observei a existência dessas redes ${ }^{16}$ sociais com sociabilidade "intensa" e encontros rotineiros. No início da pesquisa eu imaginava que as pessoas que ficavam em pequenos grupos espalhados pelo parque pertenciam a uma mesma rede, porque mantinham o mesmo estilo de vida. Porém, com o decorrer da observação, entrevistas e contato com as pessoas que pertenciam a elas é que pude perceber que elas se diferenciam e estão espalhadas por toda a extensão do Parque.

Esses atores sociais com diferentes projetos individuais, valores culturais e visão de mundo convivem no mesmo espaço típico das sociedades complexas (Velho, 1994:11-30). O que vai diferenciar essas redes sociais vai ser a forma como se organizam, a composição dos grupos (número de integrantes, idades, sexos), as práticas cotidianas e as formas de sociabilidade.

16 (Both, 1976:76) Parto do conceito de rede utilizado por essa autora quando ela analisa as relações entre famílias e redes sociais para entender como acontecem as interações e as formas de sociabilidade entre as diferentes redes no Parque da Redenção. 
Em todos os espaços observei a existência de grupos que formam uma rede que nomeei de "rede de amigos". Eles são vistos tanto no período da manhã quanto no final da tarde. Geralmente, os integrantes dessa rede ou se conhecem de instituições como colégios, cursinhos, etc, ou através de familiares e amigos em comum. São grupos heterogêneos em que não se tem idade, gênero ou classe social definida como requisito para se pertencer ao grupo. Uma prática muito comum entre os integrantes desses grupos é a de tomar chimarrão, mas também tem aquelas que dependendo do horário e temperatura do ano levam bebidas refrescantes como refrigerantes, água, etc.

Tanto pela parte da manhã quanto pela tarde encontrei a "rede dos donos de cachorros". Como na de amigos os integrantes dos grupos dessa rede podem ser vistos em vários turnos no Parque. Na maioria das vezes os donos de animais (cachorros e gatos) andam sozinhos ou acompanhados. Houve uma tarde em que conversei com os integrantes de um desses grupos que se encontrava próximo ao Chafariz. Eles eram mais ou menos uns dez jovens e cada um trazia um cachorro para passear. Foi uma situação engraçada estar no meio daqueles rapazes e moças conversando, porque ao mesmo tempo estava rodeada por cachorros de raças diferentes que nos envolviam e pulavam querendo a nossa atenção.

Os grupos de pessoas que pertencem as "redes de desportistas" são as mais encontradas no Parque e as suas formas de sociabilidade são o meu objeto de pesquisa, nesse momento.

Esses grupos ficam espalhados entre o eixo central e as laterais do Parque e, geralmente, pela manhã nos mesmos locais. São formados por homens e mulheres com idades entre 40 e 65 anos, e que pertencem às camadas médias.
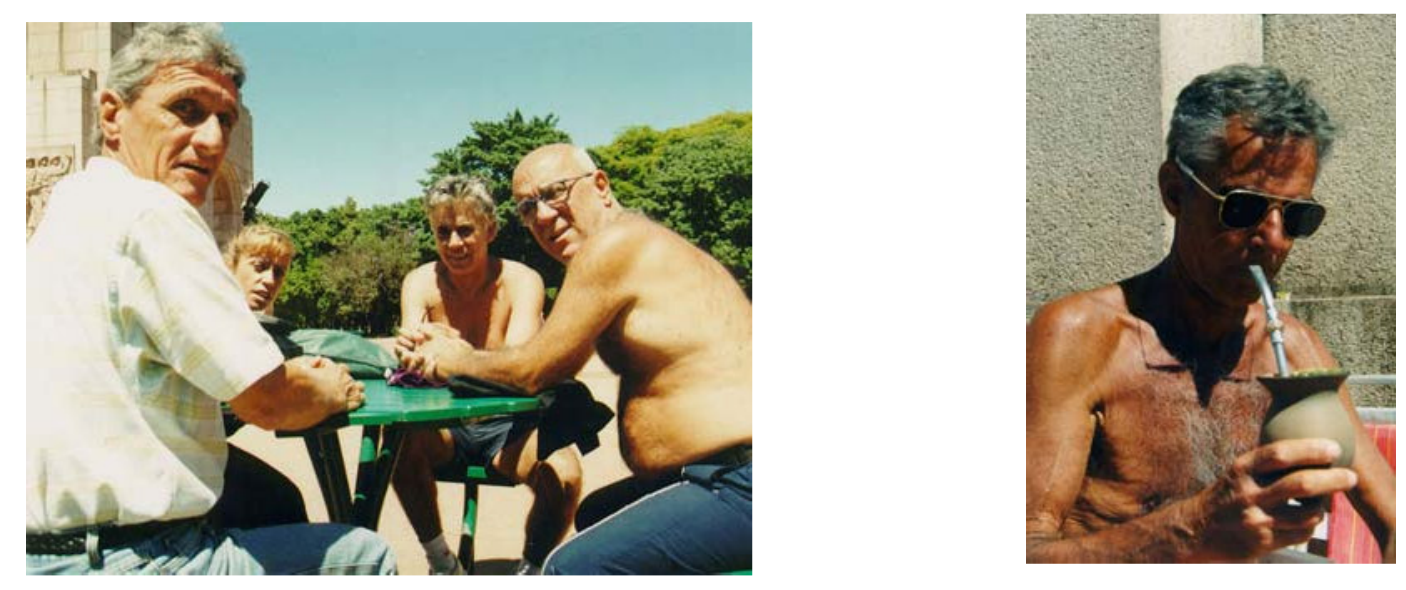
Observei que nesses grupos, além das práticas esportivas (corridas e caminhadas), a exposição do corpo ao sol é muito comum entre os seus integrantes. Essa é uma prática cotidiana e que acontece independente da temperatura do dia ou da estação do ano, desde que não seja "um daqueles dias que batem o vento minuano"17.

Nas primeiras "idas a campo" me surpreendi com a naturalidade em que as pessoas

Desses grupos, após as suas corridas despiam-se dos seus agasalhos esportivos e ficavam "to,ando sol", principal,ente no caso das mulheres acostu,adas a usar trajes de praia.

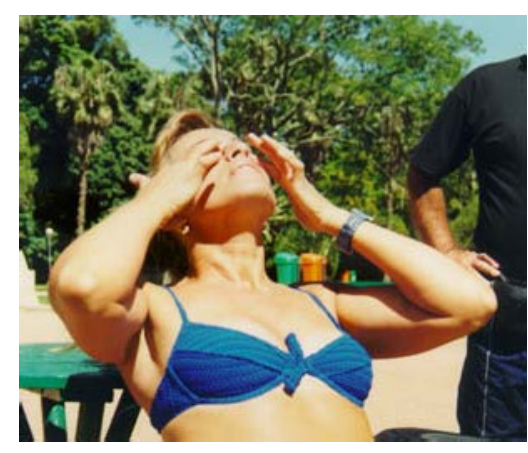

Elenir Sandra Tartas da Rosa, 2002 Fonte: Biev - Banco de Imagens e Efeitos Visuais

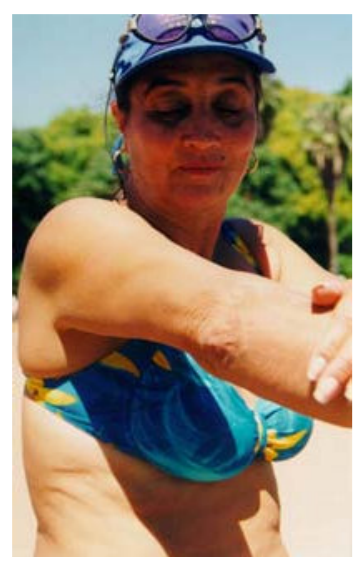

Elenir Sandra Tartas da Rosa, 2002 Fonte: Biev - Banco de Imagens e Efeitos Visuais

Para observar como se dá a sociabilidade entre as redes o meu contato e inserção em uma delas foi fundamental. O meu primeiro contato com uma das "redes dos desportistas" foi através de uma das integrantes mais antigas de uma delas. Eu a conheci num dos meus primeiros campos em que levei a máquina fotográfica. Acredito que esse instrumento tenha facilitado a minha aproximação dela. Naquele dia ela estava acompanhada de uma amiga que mais tarde vim a saber que também faz parte do seu grupo. Expliquei do que se tratava

\footnotetext{
17 Essa expressão é muito usada entre os freqüentadores quando se referem aos dias extremamente frios.
} 
a minha pesquisa falando do meu interesse em pesquisar as formas de sociabilidade encontradas no Parque e fotografar o cotidiano dos seus freqüentadores. Ela aceitou ser fotografada, entrevistada e pediu para que eu retornasse para mostrar o resultado das fotos.

Já em outro momento, essa informante me apresentou aos demais integrantes do seu grupo falando do meu interesse como pesquisadora. Mesmo sabendo da minha intenção em pesquisar as formas de sociabilidade no Parque, fui bem aceita e passei a também fazer parte do grupo. Foi através da observação participante das formas de sociabilidade desses integrantes que pude manter contato com as práticas sociais freqüentes entre eles. Ao mesmo tempo, também participo dos diferentes encontros efêmeros entre os freqüentadores e as diversas redes que se encontram no Parque.

Nesse contanto com as redes observei que as inserções de novos sujeitos a elas são feitas, geralmente, pelo intermédio de um integrante antigo da rede. Segundo Simmel, "mesmo entre pares sociais, a democracia da sociabilidade é apenas jogada" (Simmel, 1983). É pela maneira em que novas pessoas são inseridas aos grupos que o prazer desses atores sociais está ligado ao dos outros. Isso vai diferenciar os que pertencem dos que não pertencem as redes do Parque.

É necessário que se conheça alguém num desses grupos para que se possa ter a chance de vir a fazer parte dele ou não. Ou seja, se um integrante do grupo conhece alguém que não pertence à rede e o apresenta aos demais, essa pessoa pode passar a pertencer a ela também, o que independe de ela ter ou não relações com os demais grupos. Com essas inserções é que observei o surgimento de novos relacionamentos afetivos entre os que chegavam e os que eram mais antigos no grupo. Da mesma forma, os relacionamentos amorosos entre os integrantes depois de desfeitos acabam por afastar algumas pessoas do convívio com o grupo. Um exemplo dessa prática está na minha inserção que também não fugiu a essa regra que não está explícita, mas fica subentendida.

Aquelas pessoas que freqüentam o Parque, mesmo que não sejam integrantes de algum grupo, são conhecidas por todos os atores sociais pertencentes às redes ou não. Em entrevistas e no contato com os integrantes dos grupos é que esse fato ficou mais claro. A circulação de "rostos desconhecidos" é sempre percebida e muito comentada. Quando uma pessoa caminha, corre ou senta em um banco pela primeira vez, é observada pelos atores 
que integram as redes e acaba tornando-se alvo de comentários de alguns. Essa também é uma forma socializadora das relações trocadas entre os frequetadores do Parque.

Essa é a fase inicial da minha pesquisa e sei que estou dando os primeiros passos na tentativa de entender como interagem esses diferentes grupos no Parque da Redenção. Parece existir uma forma organizacional social entre os freqüentadores do Parque, os pertencentes às redes e os que não pertencem a elas. Passei a me indagar se essas relações entre esses freqüentadores acontecem através de laços de pertencimento ou não às redes sociais encontradas nesse espaço físico. Espero que com o aprofundamento das minhas relações com os grupos e com a familiarização das estratégias utilizadas na negociação dessas realidades entre os integrantes e os não-integrantes das redes esses questionamentos possam ser respondidos.

\section{REFERÊNCIAS}

BOTH, Elizabeth. Família e Rede Social. Rio de Janeiro: Livraria Francisco Alves Editora S. A., 1976.

CARNEIRO, Luiz Carlos; PENNA, Rejane; OLIVEIRA, Paulo Marsiaj. Porto Alegre De Aldeia a Metrópole. Porto Alegre: Marsiaj Oliveira e Officina da História, 1992.

COELHO, Catão. A Várzea de Outr'ora. Porto Alegre: J. de Maria Editor, 1935.

DA MATTA, Roberto. A Casa e a Rua. Rio de Janeiro: Rocco, 1997, p. 11 - 65.

HALL, Edward T. La Dimension Oculta. Enfoque Antropológico del uso del Espacio. Instituto de Estudios de Administracion Local. Madrid, 1973, p.177 - 195.

LEITE, Miriam Moreira. Retratos de Família: Leitura da Fotografia Histórica. São Paulo: Editora da Universidade de São Paulo, 2001.

LE GOFF, Jacques. História e Memória. Campinas: Ed. da UNICAMP, 1992, p.11 - 47.

MACEDO, Francisco Riopardense. História do Parque Farroupilha. In: Porto Alegre: História e Vida da Cidade. Porto Alegre: Ed. Universidade UFRGS, 1973, p. 97-141.

MONTEIRO, Charles. Parque Farroupilha: História e Memória de um Espaço de Sociabilidade no Contexto da Formação Urbana de Porto Alegre. Porto Alegre, PUC IFCH, 1989.

MONTEIRO, Charles. Parque Farroupilha: Um Lugar da Memória Coletiva e da Identidade Urbana. In: Sociedade Brasileira de Pesquisa Histórica (SBPH) - Anais da X Reunião. Curitiba, 1991.

PORTO ALEGRE, Achylles. História Popular de Porto Alegre. Porto Alegre, 1940.

SIMMEL, Georg; FERNANDES, Florestan; MORAES Filho, Evaristo de. Georg Simmel: Sociologia. São Paulo: Ática, 1983. 
VELHO, Gilberto. Individualismo e Cultura: Notas para uma Antropologia da Sociedade Contemporânea. Rio de Janeiro: Zahar Editores, 1981.

VELHO, Gilberto. Unidade e Fragmentação em Sociedades. In: Projeto e Metamorfose. Antropologia das Sociedades Complexas. Rio de Janeiro: Zahar Editores, 1994, p. 11-31. 